\title{
Effect of Different Irradiation Times on the Occlusion of Dentinal Tubules When Using a Nd:YAG Laser: An in Vitro SEM Study
}

\author{
Xiaoyu Guo ${ }^{1}$, Jinhua Yu1 ${ }^{1}$, Roger J. Smales ${ }^{2}$, Huifen Chen ${ }^{3}$, Haiyan $\mathrm{Si}^{3}$, Younong $\mathrm{Wu}^{{ }^{*}}$ \\ ${ }^{1}$ Department of Endodontics, Affiliated Hospital of Stomatology, Nanjing Medical University, Nanjing, China \\ ${ }^{2}$ School of Dentistry, Faculty of Health Sciences, The University of Adelaide, Adelaide, Australia \\ ${ }^{3}$ Institute of Stomatology, Nanjing Medical University, Nanjing, China \\ Email: yxkqgxy@163.com, roger.smales@adelaide.edu.au, sd sdbywynb@163.com
}

Received 3 February 2015; accepted 14 March 2015; published 19 March 2015

Copyright (C) 2015 by authors and Scientific Research Publishing Inc.

This work is licensed under the Creative Commons Attribution International License (CC BY).

http://creativecommons.org/licenses/by/4.0/

(c) (i) Open Access

\begin{abstract}
Objective: To evaluate the effect of different irradiation times on the occlusion of dentinal tubules when using Nd:YAG laser. Background data: Dentin hypersensitivity is a frequent problem that has limited treatment success despite many chemical and physical therapies. Methods: Four coronal dentin disks $2 \mathrm{~mm}$ thick were cut with a low-speed diamond saw from four freshly extracted intact first molars. The coronal dentin surface of each disk was divided into four regions, each approximately $2 \mathrm{~mm} \times 3 \mathrm{~mm}$. The dentin surfaces were treated with 27\% EDTA then the four regions irradiated separately in a randomized pattern with a Nd:YAG laser $(120 \mathrm{~mJ}, 5 \mathrm{~Hz})$, using irradiation times of $0 \mathrm{~s}, 20 \mathrm{~s}, 40 \mathrm{~s}$ and $60 \mathrm{~s}$, representing laser energies of $0 \mathrm{~J} / \mathrm{cm}^{2}, 200 \mathrm{~J} / \mathrm{cm}^{2}, 400 \mathrm{~J} / \mathrm{cm}^{2}$ and $600 \mathrm{~J} / \mathrm{cm}^{2}$, respectively. SEM photomicrographs were taken at $1500 \times$ and $3000 \times$ to calculate the dentinal tubule orifice occlusion rates and to measure the tubule diameters, respectively. Results: For the laser irradiation times of $0 \mathrm{~s}, 20 \mathrm{~s}, 40 \mathrm{~s}$ and $60 \mathrm{~s}$, the corresponding dentinal tubule occlusion rates were 2.05 (SD 0.29)\%, $10.01(1.71) \%, 23.58(2.51) \%$ and $90.23(2.24) \%$, respectively; and the tubule diameters were $4.18(0.32) \mu \mathrm{m}, 3.46(0.24) \mu \mathrm{m}, 1.69(0.32) \mu \mathrm{m}$ and $0.12(0.02) \mu \mathrm{m}$, respectively. There were significant differences among all groups for both measured variables ( $p \leq$ 0.005). Conclusions: Within the limitations of this in vitro study, when using a Nd:YAG laser at 120 $\mathrm{mJ}$ and $5 \mathrm{~Hz}$, an irradiation time of $60 \mathrm{~s}$ achieved the best sealing of the coronal dentinal tubule orifices.
\end{abstract}

\section{Keywords}

Nd:YAG Laser, Dentinal Tubule, Scanning Electron Microscope

\footnotetext{
${ }^{*}$ Corresponding author.
}

How to cite this paper: Guo, X.Y., Yu, J.H., Smales, R.J., Chen, H.F., Si, H.Y. and Wu, Y.N. (2015) Effect of Different Irradiation Times on the Occlusion of Dentinal Tubules When Using a Nd:YAG Laser: An in Vitro SEM Study. Open Journal of Stomatology, 5, 72-79. http://dx.doi.org/10.4236/ojst.2015.53011 


\section{Introduction}

Dentin hypersensitivity (DH) is characterized by a short, sharp and pain of rapid onset arising from exposed dentin in response to thermal, osmotic, mechanical or chemical stimuli that cannot be attributed to any other form of dental disease or defect [1]-[3]. The prevalence of DH ranges from $4 \%$ to $73 \%$ with the highest occurrence in the 20-yr to 40-yr age group, and with incisors, canines and premolars being the most commonly affected teeth [4]-[7].

The hydrodynamic theory of DH states that when stimuli induce rapid displacement of the dentinal fluid within the tubules then the fluid flow excites intradental nerves, resulting in an immediate pain response [7] [8]. According to this theory, the key to treating DH successfully is to prevent or reduce fluid flow within the tubules [5]. Therefore, using physical or chemical methods to seal exposed patent dentinal tubule orifices is a fundamental requirement. Various agents and methods have been recommended to reduce $\mathrm{DH}$ including chemical methods such as dentifrices or gels containing fluorides, potassium nitrate and oxalates, and physical methods such as dentin bonding agents [9] [10]. However, most treatments are either ineffective or only last for a short period of time [11] [12]. Because of their easy operation and more lasting DH treatment effects, several types of lasers have also been used such as the Nd:YAG laser, Er:YAG laser, $\mathrm{CO}_{2}$ laser and GaAlAs laser [13] [14].

Many in vitro and in vivo experiments have confirmed that the dentin desensitization effectiveness of the Nd:YAG laser is due to its photothermal effect, which causes dentin melting and enlarged hydroxyapatite recrystallization, thus sealing the dentinal tubules [7] [15]. There is a dose-response relationship between the effectiveness of the dentin sealing and the laser energy or density, which is closely related to the laser energy per pulse, laser frequency and irradiation time [10] [16] [17]. However, the specific quantitative effect of irradiation time does not appear to have been investigated as an independent factor, which is the objective of the present study. The null hypothesis proposed is that when specimens of coronal dentin are irradiated for various times by a Nd:YAG laser employing a fixed energy per pulse and frequency, there are no statistically significant quantitative differences in the occlusion of and the diameters of the lased dentinal tubules observed by scanning electron microscopy.

\section{Materials and Methods}

\subsection{Specimen Preparation}

The research protocol was approved by the Ethics Committee of the Affiliated Hospital of Stomatology, Nanjing Medical University, and the informed consents of the patients were obtained for the use of their teeth for research purposes. One recently extracted intact human first molar was collected from each of four patients aged from 47 to 60 years of Chinese Han nationality (three men, one woman). The molars were extracted of periodontal diseases, and the coronal dentin surface of each molar should be larger than $4 \mathrm{~mm} \times 6$ mm for further excision.

Before specimen preparation, soft tissue remnants and debris were removed from the tooth surfaces with a dental scaler (Sonicflex 2000, KaVo GmbH, Biberach, Germany). Each tooth was then sectioned transversely using a low-speed diamond saw (Isomet 1009, Buehler Ltd, Evanston, IL, USA) under tap water spray to obtain a single coronal dentin disk approximately $2 \mathrm{~mm}$ thick. The coronal dentin surface of each specimen disk was divided into four quadrants or regions, each approximately $2 \mathrm{~mm} \times 3 \mathrm{~mm}$, and numbered clockwise from 1 to 4 .

To simulate hypersensitive dentin, the smear layers created by the diamond saw were removed by immersing the dentin disks in 27\% ethylene diamine tetraacetic acid (EDTA, pH 7.4) for 2 min, followed by distilled water rinsing for $1 \mathrm{~min}$ and ultrasonic irrigation for $2 \mathrm{~min}$. This procedure was necessary to create exposed patent tubule orifices as observed in clinical cases of DH. After encoding the specimens, they were stored in sterile normal saline at $4^{\circ} \mathrm{C}$ in separate small containers until laser irradiation.

\subsection{Laser Irradiation}

The four regions on the coronal dentin surface of each specimen disk were randomly divided (using a random numbers table) into four groups labeled A, B, C and D (Table 1). For the Nd:YAG laser (Model KJZ, Hongbo Ltd, Hefei, China), the laser energy per pulse $(120 \mathrm{~mJ})$ and the laser frequency $(5 \mathrm{~Hz}) \mathrm{were}$ standardized, and variable irradiation times of $0 \mathrm{~s}, 20 \mathrm{~s}, 40 \mathrm{~s}$ and $60 \mathrm{~s}$ were used for Groups A (the control), B, C and D, respectively. These four irradiation times represented laser energy densities of $0 \mathrm{~J} / \mathrm{cm}^{2}, 200 \mathrm{~J} / \mathrm{cm}^{2}, 400 \mathrm{~J} / \mathrm{cm}^{2}$ and 600 
Table 1. Grouping results (A-D) for the four coronal dentin surface regions in each specimen disk.

\begin{tabular}{cccccc}
\hline \multirow{2}{*}{ Specimen number } & Random number & \multicolumn{5}{c}{ Dentin surface region numbers } \\
\cline { 3 - 6 } & 22 & 1 & 2 & 3 & 4 \\
\hline 1 & 06 & D & B & C & A \\
2 & 23 & D & D & C & B \\
3 & 05 & A & D & B & B \\
4 & & & & &
\end{tabular}

$\mathrm{J} / \mathrm{cm}^{2}$, respectively. The laser beam was positioned $1 \mathrm{~mm}$ above and perpendicular to the dentinal surface, aligning the beam parallel to the direction of the dentinal tubules. Scanning movements were made in buccolingual and mesiodistal directions, and vice versa. On completion, all specimens were brushed with a small soft bristle tooth brush (Oral-B, Proctor \& Gamble Co., Cincinnati, OH, USA) for 3 min then washed in deionized water before storage in a constant temperature box at $37^{\circ} \mathrm{C}$.

\subsection{Scanning Electron Microscopy (SEM)}

All specimens were dehydrated in an ascending alcohol sequence before dry storage in a constant temperature box at $37^{\circ} \mathrm{C}$ for $3 \mathrm{~d}$. The specimens were mounted on aluminum stubs and sputter-coated in gold before examination using a scanning electron microscope (Model LEO-1530, Hitachi, Tokyo, Japan). All blinded specimens were observed and photographed by one operator (XG). For each region of each specimen, typical fields were photographed at a magnification of $1500 \times$ to calculate the dentinal tubule occlusion rates, namely, the number of totally occluded dentinal tubules divided by the total number of dentinal tubules, expressed as a percentage, in each field of view. Each typical field was then photographed at an increased magnification of $3000 \times$ to measure the dentinal tubule diameters, namely, by using the image scale as a reference to measure all the tubule diameters, expressed as a mean value in $\mu \mathrm{m}$, in each field of view. All measurements were made by one evaluator (HC).

\subsection{Statistical Analysis}

The raw verified data (HS) were entered into the IBM SPSS V19 Statistics package (IBM Corp., Armonk, NY, USA) and then the four groups were analyzed blindly (HC), using the one-way ANOVA test to compare dentinal tubule orifice occlusion rates and diameters after confirming the homogeneity (Bartlett's test) of the variances $(p>0.05)$. Group A was the control group, and post hoc testing used the Dunnett test. Because the sample size was small, the Kruskal-Wallis one-way ANOVA test was also used for both the dentinal tubule occlusion rates and the dentinal tubule diameters. The numbers of occluded and non-occluded tubules in the four groups were also compared using the chi-square test. The probability level for statistical significance was set at $\alpha=0.05$.

The reliability of the evaluator (HC) was determined by repeating, after 2 weeks, an assessment of the occlusion or non-occlusion of 30 dentin tubule orifices observed in a photomicrograph of Group C (40 s), by using Cohen's Kappa test. In a similar manner, an assessment was also made of the diameters of 20 dentin tubule orifices, by using the Intraclass Correlation test.

\section{Results}

For evaluator reliability, the Kappa test value was 0.91 and the Intraclass Correlation test result was $r=0.967$ ( $p$ $<0.001$ ), indicating excellent agreements.

The results for the dentinal tubule occlusion rates are shown in Table 2 and Table 3, and typical representative images of the different appearances are shown in Figure 1. There were statistically significant differences present among all four groups for both the ANOVA test $(p<0.001)$ and the chi-square test $(p<0.005)$. The post hoc Dunnett $p$-values were all $<0.001$. The Kruskal-Wallis one-way ANOVA $p$-value was 0.003 . The dentinal tubule occlusion rates increased significantly and exponentially with increasing irradiation times, in particular between $40 \mathrm{~s}$ and $60 \mathrm{~s}$. 
Table 2. Dentinal tubule occlusion rates (\%) after irradiation for different times.

\begin{tabular}{cccc}
\hline Time & Occlusion rate & F-value & $p$-value \\
\hline Group A (0 s) & $2.05(0.29)^{\mathrm{a}}$ & 1798.89 & $<0.001$ \\
Group B (20 s) & $10.01(1.71)$ & & \\
Group C (40 s) & $23.58(2.51)$ & & \\
Group D (60 s) & $90.23(2.24)$ & & \\
\hline
\end{tabular}

${ }^{\mathrm{a}}$ Mean (Standard Deviation).

Table 3. Number of occluded dentinal tubules after irradiation for different times.

\begin{tabular}{ccccccc}
\hline \multirow{2}{*}{ Time } & \multicolumn{5}{c}{ Dentin surface region numbers } & Chi-square \\
\cline { 2 - 6 } & 1 & 2 & 3 & 4 & value & $p$-value \\
\hline A (0 s) & $3(152)^{\mathrm{a}}$ & $3(162)$ & $3(158)$ & $4(162)$ & 45.8 & $<0.005$ \\
B (20 s) & $10(124)$ & $10(110)$ & $12(104)$ & $15(132)$ & & \\
C (40 s) & $24(110)$ & $28(120)$ & $29(132)$ & $34(125)$ & & \\
D (60 s) & $90(103)$ & $95(105)$ & $104(112)$ & $101(112)$ & & \\
\hline
\end{tabular}

${ }^{\mathrm{a}}$ Total number of dentinal tubules (in parentheses).
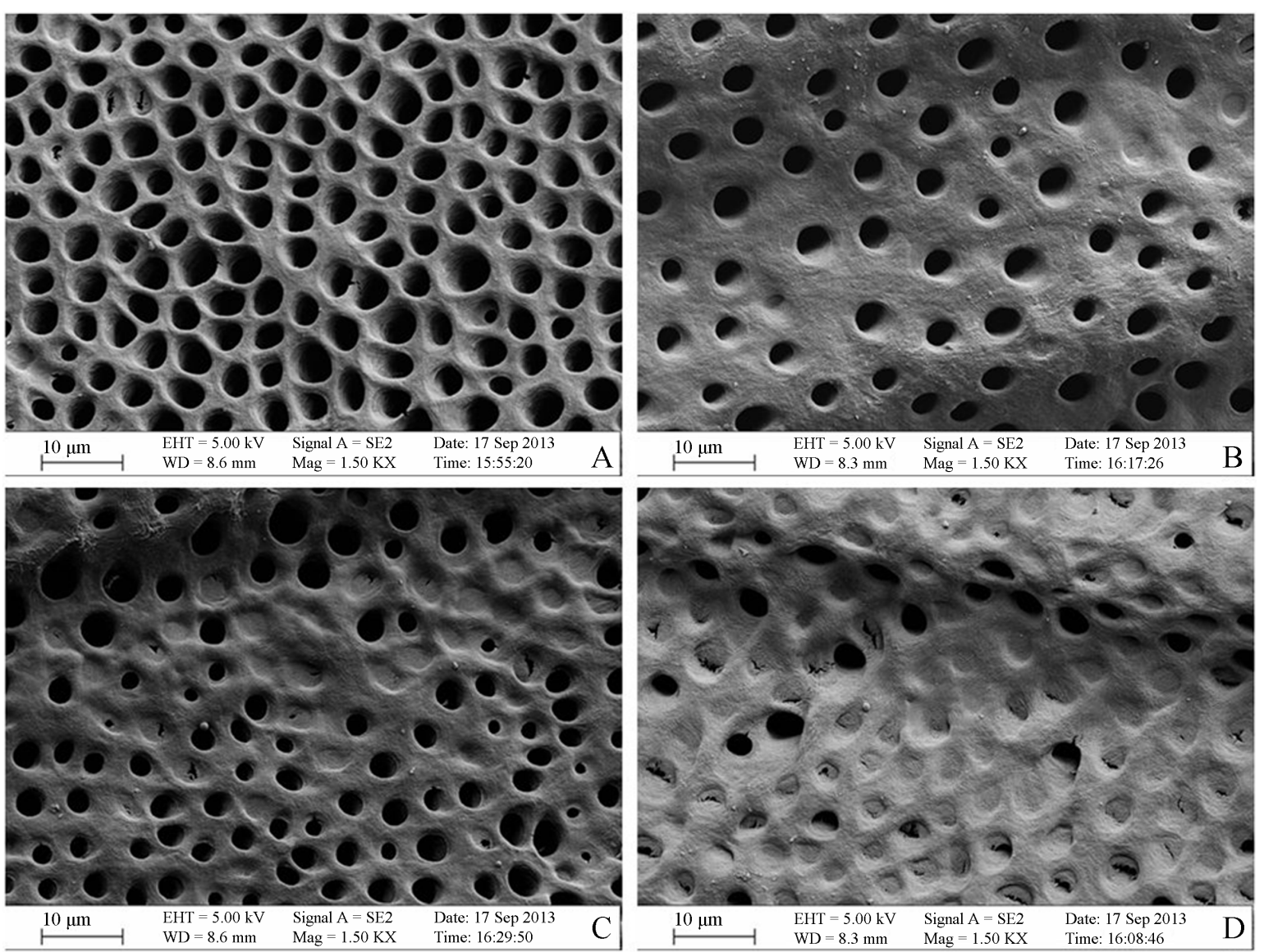

Figure 1. Dentinal tubule occlusion appearances after irradiation using a Nd:YAG laser for different times (Original magnification $1500 \times)$. 
The findings for the dentinal tubule diameters are shown in Table 4, and typical representative images of the different appearances are shown in Figure 2. There were statistically significant differences present among all four groups $(p<0.001)$. The post hoc Dunnett $p$-value was 0.005 between Group A and B, and $<0.001$ between Group A and Groups C and D. The Kruskal-Wallis one-way ANOVA p-value was 0.003 . The mean dentinal tubule diameters decreased significantly and linearly with increasing irradiation times.

\section{Discussion}

Transversely cut dentin sections from the coronal region of four molar teeth were used for the four specimen disks to standardize as much as possible the tubule directions, diameters and densities in the specimens. Differences between the four specimen disks were further reduced by a randomization of the four dentin test quadrants or regions on each specimen's coronal surface. As in previous studies [7] [9] [18], the smear layers produced by the diamond saw on the surfaces of the dentin specimens were removed by EDTA to avoid influencing the ef-

Table 4. Dentinal tubule diameters $(\mu \mathrm{m})$ after irradiation for different times.

\begin{tabular}{cccc}
\hline Time & Tubule diameter & F-value & $p$-value \\
\hline Group A (0 s) & $4.18(0.32)^{\mathrm{a}}$ & 202.12 & $<0.001$ \\
Group B (20 s) & $3.46(0.24)$ & & \\
Group C (40 s) & $1.69(0.32)$ & & \\
Group D (60 s) & $0.12(0.02)$ & & \\
\hline
\end{tabular}

${ }^{\mathrm{a}}$ Mean (Standard Deviation).
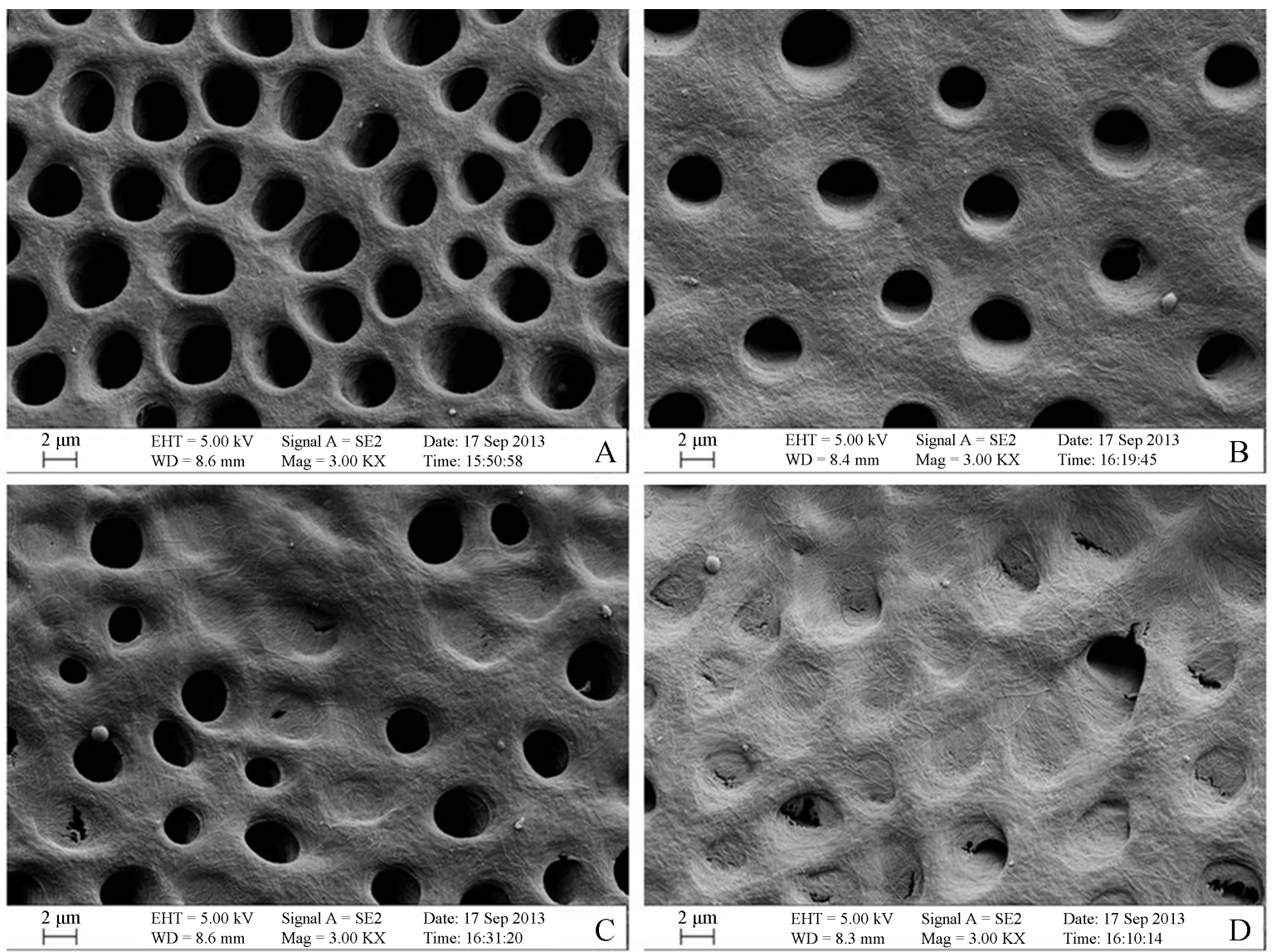

Figure 2. Dentinal tubule diameters after irradiation using a Nd:YAG laser for different times (Original magnification $3000 \times)$. 
fects of Nd:YAG laser irradiation and to simulate the exposed patent dentinal tubules found in instances of DH. A SEM magnification of $1500 \times$ was chosen for counting the number of occluded tubules in each selected field of view (Table 3). The magnification chosen reduced considerably the workload associated with counting tubules at a lower magnification of $1000 \times$, as was used in a previous study [7]. Because the mean diameters of the coronal tubules in normal circumstances are only approximately $3-5 \mu \mathrm{m}$ [18], an increased magnification of $3000 \times$ was chosen for the measurement of their diameters. To avoid operator bias, the selection of the SEM fields and the subsequent data collection and statistical analysis were done independently by two blinded operators.

The present study confirmed the findings of several in vitro studies that showed an increased occlusion of dentinal tubule orifices with increased Nd:YAG laser irradiation energies. In one study, [10] when the power of the Nd:YAG laser was increased from $0.5 \mathrm{~W}$ to $1.0 \mathrm{~W}$ (fixed factors: $10 \mathrm{~Hz}, 30 \mathrm{~s}$ ), there was a significant increase at $1.0 \mathrm{~W}$ in the percentages of occluded dentinal tubule orifices observed. One other study, [16] reported a progressive increase in dentinal tubule occlusion rates when the irradiation energies of the Nd:YAG laser were increased from $41.6 \mathrm{~J} / \mathrm{cm}^{2}$ to $83 \mathrm{~J} / \mathrm{cm}^{2}, 125 \mathrm{~J} / \mathrm{cm}^{2}$ and $167 \mathrm{~J} / \mathrm{cm}^{2}$. This dose-effect relationship was also clearly shown in the present study where the irradiation times were increased progressively from $0 \mathrm{~s}$ to $20 \mathrm{~s}, 40 \mathrm{~s}$ and 60 s (fixed factors: $120 \mathrm{~mJ}, 5 \mathrm{~Hz}$ ). The morphological changes observed were an exponential increase in the dentinal tubule orifice occlusion rates and a concomitant linear decrease in the tubule orifice diameters (Table 2 and Table 4, Figure 1 and Figure 2).

Lasing the surface of exposed dentinal tubules with a Nd:YAG laser at an energy of $30 \mathrm{~mJ}$ with 10 pulses per second for a stroke resulted in the melting of dentin and closure of the exposed tubules without surface cracking, and was associated with a tubule sealing depth of $3-4 \mu \mathrm{m}$ [15]. The SEM dentin surface melting was similar to that obtained in an earlier in vivo study which used the same energy settings for 2 min [11]. Excessive laser irradiation energies can cause cracks and fissures in dentin surfaces, which were not observed in the present study, and may also potentially damage the pulp. However, clinically, pulpal damage is unlikely if the power of the laser is less than $1.0 \mathrm{~W}$ [13]. Laser energies higher than $396 \mathrm{~J} / \mathrm{cm}^{2}$ may lead to irreversible structural damage of the dentin surface such as spherical protrusions, cracks, pits and carbonization [17]. In addition, the absorbed laser energy may elevate the temperature of the whole tooth and, when the rising temperature exceeds $5^{\circ} \mathrm{C}$, may lead to irreversible damage to the pulp. Therefore, recommendations have been made to limit laser parameters to an output power of $0.5-1.0 \mathrm{~W}$, a laser energy of $60-150 \mathrm{~mJ}$ and a frequency of $10-15 \mathrm{~Hz}$ [7].

In the present study, because the dentinal tubule orifice occlusion was approximately $90 \%$ after $60 \mathrm{~s}$ irradiation, there is no rational reason to extend this time, when using a Nd:YAG laser with fixed factors of $120 \mathrm{~mJ}$ and $5 \mathrm{~Hz}$, in attempts to achieve $100 \%$ tubule occlusion [17]. Different teeth and tooth regions have very different physical and chemical properties [19], and such futile attempts may well result in severe irreversible damage to the surface and subsurface of the dentin and to the dental pulp. Subsurface and pulpal effects in the present in vitro study were not evaluated, and the findings from the small sample size, though clearly demonstrating a statistically significant trend of increasing dentinal tubule orifice occlusion and narrowing with increasing laser irradiation times, should be confirmed by larger studies.

\section{Conclusions}

The null hypothesis was rejected as there were significantly increased dentinal tubule orifice occlusion rates and decreased tubule diameters from progressively increasing the Nd:YAG irradiation times from $0 \mathrm{~s}$ to $60 \mathrm{~s}(p \leq$ 0.005). Optimum sealing of the coronal dentinal tubules was observed at the $60 \mathrm{~s}$ exposure time.

The four groups (A, B, C, D) in the figure represented laser irradiation for different times of $0 \mathrm{~s}, 20 \mathrm{~s}, 40 \mathrm{~s}$ and $60 \mathrm{~s}$, respectively. In Group A (0 s), almost all of the dentinal tubule orifices are patent. In Group B (20 s), a few dentinal tubule orifices are totally occluded. In Group C (40 s), many dentinal tubule orifices are totally occluded. In Group D (60 s), most of the dentinal tubule orifices are totally occluded and some remain partially occluded (Original magnification 1500×).

The four groups (A, B, C, D) in the figure represented laser irradiation for different times of $0 \mathrm{~s}, 20 \mathrm{~s}, 40 \mathrm{~s}$ and $60 \mathrm{~s}$, respectively. In Group A (0 s), after EDTA immersion with removal of the smear layers, the dentinal tubule orifices are patent and wide. In Group B (20 s), the dentinal tubule orifices are significantly narrower. In Group C (40 s), many dentinal tubule orifices are totally occluded and the remainder show further significantly narrowing. In Group D (60 s), most of the dentinal tubule orifices are totally occluded and the remainder barely pa- 
tent (Original magnification 3000×).

\section{Acknowledgements}

We would like to thank the staff of the Paleontology Research Institute of Nanjing for assistance with the SEM.

\section{Author Disclosure Statement}

No competing financial or other interests exist.

\section{References}

[1] Holland, G.R., Narhi, M.N., Addy, M., Gangarosa, L. and Orchardson, R. (1997) Guidelines for the Design and Conduct of Clinical Trials on Dentine Hypersensitivity. Journal of Clinical Periodontology, 24, 808-813. http://dx.doi.org/10.1111/j.1600-051X.1997.tb01194.X

[2] Orchardson, R. and Gillam, D.G. (2006) Managing Dentin Hypersensitivity. The Journal of the American Dental Association, 137, 990-998. http://dx.doi.org/10.14219/jada.archive.2006.0321

[3] Dilsiz, A., Canakci, V., Ozdemir, A. and Kaya, Y. (2009) Clinical Evaluation of Nd:YAG and 685-nm Diode Laser Therapy for Desensitization of Teeth with Gingival Recession. Photomedicine and Laser Surgery, 27, 843-848. http://dx.doi.org/10.1089/pho.2008.2395

[4] Canakci, C.F. and Canakci, V. (2007) Pain Experienced by Patients Undergoing Different Periodontal Therapies. The Journal of the American Dental Association, 138, 1563-1573. http://dx.doi.org/10.14219/jada.archive.2007.0105

[5] Gholami, G.A., Fekrazad, R., Esmaiel-Nejad, A. and Kalhori, K.A. (2011) An Evaluation of the Occluding Effects of Er;Cr:YSGG, Nd:YAG, $\mathrm{CO}_{2}$ and Diode Lasers on Dentinal Tubules: A Scanning Electron Microscope in Vitro Study. Photomedicine and Laser Surgery, 29, 115-121. http://dx.doi.org/10.1089/pho.2009.2628

[6] Al-Saud, L.M. and Al-Nahedh, H.N. (2012) Occluding Effect of Nd:YAG Laser and Different Dentin Desensitizing Agents on Human Dentinal Tubules in Vitro: A Scanning Electron Microscopy Investigation. Operative Dentistry, 37, 340-355. http://dx.doi.org/10.2341/10-188-L

[7] Palazon, M.T., Scaramucci, T., Aranha, A.C., Prates, R.A., Lachowski, K.M., Hanashiro, F.S., et al. (2013) Immediate and Short-Term Effects of In-Office Desensitizing Treatments for Dentinal Tubule Occlusion. Photomedicine and Laser Surgery, 31, 274-282. http://dx.doi.org/10.1089/pho.2012.3405

[8] Brännström, M. and Astrom, A. (1972) The Hydrodynamics of the Dentine; Its Possible Relationship to Dental Pain. International Dental Journal, 22, 219-227.

[9] Farmakis, E.-R.T., Kozyrakis, K, Khabbaz, M.G., Schoop, U., Beer, F. and Moritz, A. (2012) In Vitro Evaluation of Dentin Tubule Occlusion by Denshield and Neodymium-Doped Yttrium-Aluminum-Garnet Laser Irradiation. Journal of Endodontics, 38, 662-666. http://dx.doi.org/10.1016/j.joen.2012.01.019

[10] Farmakis, E.-R.T., Beer, F., Kozyrakis, K., Pantazis, N. and Moritz, A. (2013) The Influence of Different Power Settings of Nd:YAG Laser Irradiation, Bioglass and Combination to the Occlusion of Dentinal Tubules. Photomedicine and Laser Surgery, 31, 54-58. http://dx.doi.org/10.1089/pho.2012.3333

[11] Lan, W.-H., Lee, B.-S., Liu, H.-C. and Lin, C.-P. (2004) Morphological Study of Nd:YAG Laser Usage in Treatment of Dentinal Hypersensitivity. Journal of Endodontics, 30, 131-134. http://dx.doi.org/10.1097/00004770-200403000-00001

[12] Malkoc, M.A. and Sevimay, M. (2012) Evaluation of Mineral Content of Dentin Treated with Desensitizing Agents and Neodymium Yttrium-Aluminium-Garnet (Nd:YAG) Laser. Lasers in Medical Science, 27, 743-748. http://dx.doi.org/10.1007/s10103-011-0954-6

[13] Birang, R., Poursamimi, J., Gutknecht, N., Lampert, F. and Mir, M. (2007) Comparative Evaluation of the Effects of Nd:YAG and Er:YAG Laser in Dentin Hypersensitivity Treatment. Lasers in Medical Science, 22, 21-24. http://dx.doi.org/10.1007/s10103-006-0412-Z

[14] He, S., Wang, Y., Li, X. and Hu, D. (2011) Effectiveness of Laser Therapy and Topical Desensitising Agents in Treating Dentine Hypersensitivity: A Systematic Review. Journal of Oral Rehabilitation, 38, 348-358. http://dx.doi.org/10.1111/j.1365-2842.2010.02193.x

[15] Liu, H.-C., Lin, C.-P. and Lan, W.-H. (1997) Sealing Depth of Nd:YAG Laser on Human Dentinal Tubules. Journal of Endodontics, 23, 691-693. http://dx.doi.org/10.1016/S0099-2399(97)80403-7

[16] Song, Y.X., Liu, L.C., He, H.X., Xiong, H. and An, J.P. (2002) Dentinal Morphological Changes after Nd:YAG Laser Irradiation. West China J. Stomatology. 20, 429-431. (In Chinese)

[17] Zapletalová, Z., Perina Jr., J., Novotný, R. and Chmelícková, H. (2007) Suitable Conditions for Sealing of Open Den- 
tinal Tubules Using a Pulsed Nd:YAG laser. Photomedicine and Laser Surgery, 25, 495-499. http://dx.doi.org/10.1089/pho.2007.2085

[18] Abed, A.M., Mahdian, M., Seifi, M., Ziaei, S.A. and Shamsael, M. (2011) Comparative Assessment of the Sealing Ability of Nd:YAG Laser versus a New Desensitizing Agent in Human Dentinal Tubules: A Pilot Study. Odontology, 99, 45-48. http://dx.doi.org/10.1007/s10266-010-0136-1

[19] Lan, W.-H., Liu, H.-C. and Lin, C.-P. (1999) The Combined Occluding Effect of Sodium Fluoride Varnish and Nd:YAG Laser Irradiation on Human Dentinal Tubules. Journal of Endodontics, 25, 424-426. http://dx.doi.org/10.1016/S0099-2399(99)80271-4 